\title{
Factors Affecting the Vertical Distribution of Oribatid Mites (Acari: Oribatida) in Ismailia Governorate, Egypt
}

\author{
H. M. El-Sharabasy \\ Plant Frotection Dept., Faculty of Agriculture, Suez Canal University, Ismailia Egypt
}

\begin{abstract}
The vertical distribution of soil oribatid mites and its dependence on ecological parameters such as soil temperature, moisture, $\mathrm{pH}$ and organic matter content were studied in an age sequence of 22-year-old Mangifera indica $\mathrm{L}$ plantations in Ismailia, down to a depth of $30 \mathrm{~cm}$. The results showed that the numbers of total cribatid mites exhibited a gradual decrease trend with depth. The number of oribatid mite species was significantly lower in $20-30 \mathrm{~cm}$ depth than the tope layers $(p<0.05$ ). Pergalummna flagellate Grandjean and Oppiella nova (Oudemans) dominated in the upper $10 \mathrm{~cm}$ soil and their numbers strongly decreased with depth. Most of oribatid mites had an annual fluctuation in their abundance and population changes, which related to seasonal changes in the temperature and moisture contents of the soil. Soil moisture was positively correlated with total mites; while soil temperature had negative correlation.
\end{abstract}

Key Words: Oribatid mites; Vertical distribution; Seasonal changes; soil factors.

\section{INTRODUCTION}

The great diversity of oribatid community in soil and litter has awaked much attention. They are considered fundamental components of soils playing a key role in many essential processes, including decomposition, nutrient cycling, and development of soil structure. The use of soil mites as indicators of soil quality and soil health may benefit greatly (E1Sharabasy and Ibrahim, 2010). Behan-Pelletier (1999) identified orbatids as indicators for monitoring changes in soil quality. The vertical distribution of soil oribatid mites has been poorly studied despite their importance in understanding the interrelationship between the surface and deeper soil layers. The identities of factors that determine a pattern of mite species richness have been of longstanding interest to ecologists and are of fundamental importance to the management and preservation of biodiversity (Siepel 1996; Banerjee et al., 2009). Vertical distribution and population abundance of oribatid mites in soil vary in relation to various environmental factors like temperature, moisture, organic matters, nutrient availibilty, etc. (Frouz et al., 2004).

Vertical distribution of oribatid mites in different habitats has been examined (Perdue and Crossley, 1990; Edsberg and Hagvar, 1999). However, a very few studies on the vertical distribution of oribatid mites and the relationships between their populations and the abiotic environment in Egyptian plantations were undertaken (Wafa et al., 1965 and Abo-Korah 1979). So, the aim of the present study is to provide information on factors that affect the vertical distribution and seasonal changes of oribatid mite species in Suez Canal area.

\section{MATERIALS AND METHODS}

\section{Study site:}

The study was conducted from March 2011 to February 2012 at the experimental farm of Agriculture college, Ismailia, Egypt, $\left(30^{\circ} 58^{\prime} \mathrm{N}\right.$ and $32^{\circ} 23^{\prime} \mathrm{E}$ and elevation above sea level, $13 \mathrm{~m}$ ). The climate is characterized by aridity with long hot rainles summers, mild winter and low amount of rainfall, $50 \mathrm{~mm}$ annually. Annual mean air temperature is $27.61{ }^{\circ} \mathrm{C}$ and annual mean relative humidity is $82.33 \%$. Figure 1 shows the monthly air temperature and relative humidity during the study period from the meteorological station. The field selected for examination is a mango orchard, where the mango trees of 22-year-old. Mangifera indica L. trees are situated in rows at equidistance of five meters each. Some weeds growing from time to time between rows and these were mainly; Melilotus indica L. ALL., Cyperus rotundus L. and Cynodom dactylon (L.) Pers. and Convolvulus arvensis L. The soil classified, following the Soil Survey Staff (2003), as sandy loam type, with $87.4-97.3 \%$ sand, $2.110 .2 \%$ silt and $0.7-2.3 \%$ clay.

\section{Sampling and extraction technique:}

Three $30-\mathrm{cm}$ deep core samples were collected using a circular corer $5.5 \mathrm{~cm}$ in diameter. Each 30 $\mathrm{cm}$ column of core sample was divided into $10-\mathrm{cm}$ top, middle and bottom section. Collected samples were extracted for $48 \sim 72$ hours in the laboratory for oribatid mites using modified Tullgren-funnel. After extraction, colleted mites were transferred to $70 \%$ ethanol and identified according to Balogh (1972). Additional samples were collected at the same depths and transported to the laboratory in plastic bags and weighed, dried at $105^{\circ} \mathrm{C}$ for $5 \mathrm{~h}$, and 
weighed again to determine soil moisture. Soil $\mathrm{pH}$, Electrical Conductivity (EC) and Organic matter content (OMC) were determined and estimated by Walkely and Black method according to Jackson (1958), Soil temperatures were taken by inserting the bulbs of mercury-in-glass thermometers into the soil at $30-\mathrm{cm}$ deep while; soil samples were collected. Temperature was read while; the thermometers were still in place.

\section{Data analyses:}

The diversity of oribatid mite communities was expressed by the Shannon-Wiener index $\left(\mathrm{H}^{\prime}\right)$ (Magurran, 1988) and the evenness of community was calculated by Pielou's J index (Pielou, 1984). Two - way ANOVA was used to examine differences between habitats and or sampling date. All statistical analysis was done using COSTAT software, and differences between means were assessed using the Tukey test. Pearson's correlation coefficients were determined between monthly mean of mite densities and monthly edaphic parameters.

\section{RESULTS AND DISCUSSION}

\section{Environmental variables:}

Table 1 shows the physicochemical parameters of the soil. Soil temperature in the top layer $(0-10 \mathrm{~cm})$ was significantly higher $(p<0.05, \mathrm{df}=5)$ than the other layers $(10-20$ and $20-30 \mathrm{~cm})$, in accordance with the general trends observed in air temperature. The maximum soil temperature values were recorded in summer season in the tree soil layers $\left(47.5 \pm 5.01,37.5 \pm 0.77\right.$ and $33.5 \pm 1.15^{\circ} \mathrm{C}$, respectively), whereas the lowest values were recorded in winter $(16.5 \pm 1.11,16.2 \pm 1.07$ and $16.3 \pm 2.51{ }^{\circ} \mathrm{C}$, respectively). The soil moisture of the top layer was slightly higher than in the bottom layers. The soil moisture ranged from $51.8 \pm 2.83$ to $65.7 \pm 3.05$ in the top layer and this wet period coincided with a decrease in soil temperature. Values showed significant differences with the other sampling dates $(p<0.05, \mathrm{df}=5)$. The study area contained less of organic matter content (OMC \%). The values of soil $\mathrm{pH}$ and $\mathrm{EC}$ showed similar trend, and no significant differences were detected, with higher values found for the $20-30-\mathrm{cm}$ depth.

\section{Total number of oribatid mites:}

. A total of 314 individuals of oribatid species were obtained (individuals $500 / \mathrm{g}$ dry soil), and it reached a maximum mean density at $0-10 \mathrm{~cm}$ depth; $71.34 \%$ was from a depth $0-10 \mathrm{~cm}, 19.11 \%$ was from $10-20 \mathrm{~cm}$ and $4.14 \%$ was from $20-30 \mathrm{~cm}$. It was found that the total number of oribatid mites in mango plantations decreased with increasing soil depth. The majority of samples were dominated by the family Oppiidae which comprised $24.84 \%$ of the overall community. Significant differences in the total number of oribatid mites were observed among treatments and depths $(P<0.05, \mathrm{df}=5)$, where $0-10$ $>10-20>20-30 \mathrm{~cm}$. Table 2 lists the mite densities of all species occurred at each soil layers.

\section{Seasonal changes in total numbers:}

Figure 2 shows the annual changes for each species obtained in the three soil layers. The lowest abundance of oribatid mite population was recorded during the summer season, when soil moisture was also relatively low, while the population maxima was recorded in the period of November-March (late autumn, winter and early spring) (Figs. 2 from a to $\mathrm{g}$, respectively). Oppiella nova (Oudemans) was the dominant species during time sampling and showed its highest populations in the three depths. The maximum number was recorded in January, December and February $(69.64,17.86$ and $12.5 \%$, respectively), coincidental with the lower temperatures (Fig. 2c). Pergalummna flagellate Grandjean ranked the second, $(62.65,18.1$ and 19.3 $\%$, respectively) (Table 2a). Scheloribates lavigatus (Koch) had its peak during winter months. On the hand, all of Epilohmannia cylindrical Berlese , Cosmochthonius lantus (Michael) Ctenacarus araneola (Grandjean) Aphilacarus acarinus (Berlese) and Phthiracarus sp. not recorded from May to September during the whole experimental period. The period from May to September seemed to have been critical for the survival of all oribatid species as no individuals were found in those months.

\section{Vertical distribution:}

In total, 8 oribatid genera and species were identified in the samples taken for the vertical distribution study. The relative abundance of these genera in each soil layer is presented in Fig. 3. Density of oribatid mites decreased with soil depth. In total $71.34 \%$ of the mites were presented in the top soil depth, $0-10 \mathrm{~cm}$ and 19.11 and $9.55 \%$ at depth of 10 -20 and $20-30 \mathrm{~cm}$, respectively. Oribatid species $P$. flagellate and Oppiella nova prevailed in the upper soil layer and decreased in numbers with soil depth, and found in the three soil layers, with coincidental with the higher temperatures contained significantly higher numbers $(P<0.05) \mathrm{n}$ nearly all sampling months. Epilohmannia cylindrical Berlese, Ctenacarus araneola (Grandjean) Aphilacarus acarinus (Berlese) and Phthiracarus $s p$ were found only in the top layer $(0-10 \mathrm{~cm})$ while not recorded in the others. 
Table (1): Monthly variation of edaphic factors in different soil depths of the study site during the collection period.

\begin{tabular}{|c|c|c|c|c|c|}
\hline 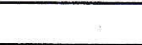 & Soil Temperature $\left({ }^{\circ} \mathrm{C}\right)$ & Soil moisture \% & $\mathrm{OMC} \%$ & $\mathrm{pH}$ & E.C $\%$ \\
\hline \multicolumn{6}{|l|}{$0-10 \mathrm{~cm}$} \\
\hline Spring & $34.5 \pm 0.58^{\mathrm{a}}$ & $51.8 \pm 2.83^{\mathrm{a}}$ & $0.51 \pm 0.02^{\mathrm{a}}$ & $7.17 \pm 0.37^{\mathrm{ab}}$ & $0.92 \pm 0.19^{b}$ \\
\hline Summer & $47.5 \pm 5.01^{b}$ & $55.3 \pm 1.01^{\mathrm{ab}}$ & $0.55 \pm 0.01^{\mathrm{b}}$ & $6.91 \pm 0.28^{b}$ & $0.85 \pm 0.27^{b}$ \\
\hline Autumn & $26.5 \pm 6.29^{\mathrm{ab}}$ & $55.7 \pm 4.76^{\mathrm{a}}$ & $0.45 \pm 0.03^{\mathrm{ab}}$ & $7.41 \pm 0.22^{b}$ & $0.96 \pm 0.11^{\mathrm{ab}}$ \\
\hline Winter & $16.5 \pm 1.11^{\mathrm{c}}$ & $65.7 \pm 3.05^{b}$ & $0.59 \pm 0.02^{\mathrm{ab}}$ & $7.26 \pm 0.13^{\mathrm{a}}$ & $0.93 \pm 0.27^{a}$ \\
\hline \multicolumn{6}{|l|}{$10-20 \mathrm{~cm}$} \\
\hline Spring & $32.5 \pm 4.71^{\mathrm{a}}$ & $53.2 \pm 5.15^{\mathrm{a}}$ & $0.41 \pm 0.01^{\mathrm{a}}$ & $7.33 \pm 0.22^{\mathrm{a}}$ & $0.89 \pm 0.23^{\mathrm{a}}$ \\
\hline Summer & $37.5 \pm 0.77^{\mathrm{ab}}$ & $55.6 \pm 1.36^{\mathrm{a}}$ & $0.51 \pm 0.01^{b}$ & $7.49 \pm 0.29^{\mathrm{a}}$ & $0.93 \pm 0.21^{\mathrm{a}}$ \\
\hline Autumn & $21.5 \pm 5.06^{\mathrm{b}}$ & $55.2 \pm 5.54^{\mathrm{a}}$ & $0.48 \pm 0.06^{\mathrm{ab}}$ & $7.41 \pm 0.18^{b}$ & $0.89 \pm 0.32^{\mathrm{b}}$ \\
\hline Winter & $16.2 \pm 1.07^{\mathrm{c}}$ & $61.1 \pm 2.91^{\mathrm{b}}$ & $0.57 \pm 0.05^{\mathrm{c}}$ & $6.61 \pm 0.50^{b}$ & $0.91 \pm 0.25^{b}$ \\
\hline \multicolumn{6}{|l|}{$20-30 \mathrm{~cm}$} \\
\hline Spring & $26.5 \pm 1.91^{\mathrm{a}}$ & $51.2 \pm 4.33^{\mathrm{a}}$ & $0.41 \pm 0.01^{\mathrm{a}}$ & $7.51 \pm 0.25^{\mathrm{ab}}$ & $0.86 \pm 0.50^{\mathrm{a}}$ \\
\hline Summer & $33.5 \pm 1.15^{\mathrm{ab}}$ & $57.3 \pm 1.78^{\mathrm{b}}$ & $0.48 \pm 0.04^{\mathrm{ab}}$ & $7.96 \pm 0.38^{\mathrm{a}}$ & $0.75 \pm 0.74^{a}$ \\
\hline Autumn & $17.5 \pm 2.5^{\mathrm{b}}$ & $56.6 \pm 5.25^{\mathrm{ab}}$ & $0.47 \pm 0.05^{\mathrm{b}}$ & $8.04 \pm 0.42^{\mathrm{a}}$ & $0.81 \pm 0.62^{\mathrm{ab}}$ \\
\hline Winter & $15.3 \pm 2.51^{\mathrm{ab}}$ & $62.3 \pm 3.61^{\mathrm{ab}}$ & $0.59 \pm 0.06^{\mathrm{c}}$ & $7.68 \pm 0.21^{b}$ & $0.77 \pm 0.41^{b}$ \\
\hline
\end{tabular}

Means and standard deviation from three replicates; different letters in a column at each depth indicate significant differences as assessed by Tukey's multiple range test $(\mathrm{P}<0.05)$.

Table (2): Composition and individuals of oribatid mite species of the study site at three soil depthes (individuals 500/g soil).

\begin{tabular}{|c|c|c|c|}
\hline Snecies & Soil depth & & \\
\hline species & $0-10 \mathrm{~cm}$ & $10-20 \mathrm{~cm}$ & $20-30 \mathrm{~cm}$ \\
\hline $\begin{array}{l}\text { Galumnidae Jacot, } 1925 \\
\text { Pergalummnn flagellate Grandjean }\end{array}$ & 52 & 15 & 16 \\
\hline $\begin{array}{l}\text { Scheloribatidae Grandjean, } 1953 \\
\text { Scheloribates lavigatus (Koch) }\end{array}$ & 24 & 13 & 0 \\
\hline $\begin{array}{l}\text { Oppiidae Grandjean, } 1954 \\
\text { Oppiella nova (Oudemans) }\end{array}$ & 78 & 20 & 14 \\
\hline $\begin{array}{l}\text { Epilohmanniidae Oudemans, } 1923 \\
\text { Epilohmannia cylindrica } \text { Berlese }\end{array}$ & 26. & 12 & 0 \\
\hline $\begin{array}{c}\text { Cosmochthoniidae, Grandjean, } 1947 \\
\text { Cosmochthonius lantus (Michael) }\end{array}$ & 15 & 0 & 0 \\
\hline $\begin{array}{l}\text { Ctenacaridae Grandjean, } 1954 \\
\text { Ctenacarus araneola (Grandjean) }\end{array}$ & 12 & 0 & 0 \\
\hline $\begin{array}{l}\text { Aphilacaridae Grandjean, } 1954 \\
\text { Aphilacarus acarinus (Berlese) }\end{array}$ & 11 & 0 & 0 \\
\hline $\begin{array}{l}\text { Phthiracaridae Petry, } 1841 \\
\text { Phthiracarus sp. }\end{array}$ & 26 & 0 & 0 \\
\hline Total & $\frac{224}{1.17 \pm 0.03}$ & 60 & 30 \\
\hline$\frac{H^{\prime}}{S}$ & $\frac{1.17 \pm 0.03}{8}$ & $\frac{1.41 \pm 0.09}{4}$ & $\frac{1.09 \pm 0.11}{2}$ \\
\hline $\mathbf{J}$ & $0.82 \pm 0.02$ & $0.68 \pm 0.07$ & $0.96 \pm 0.05$ \\
\hline
\end{tabular}

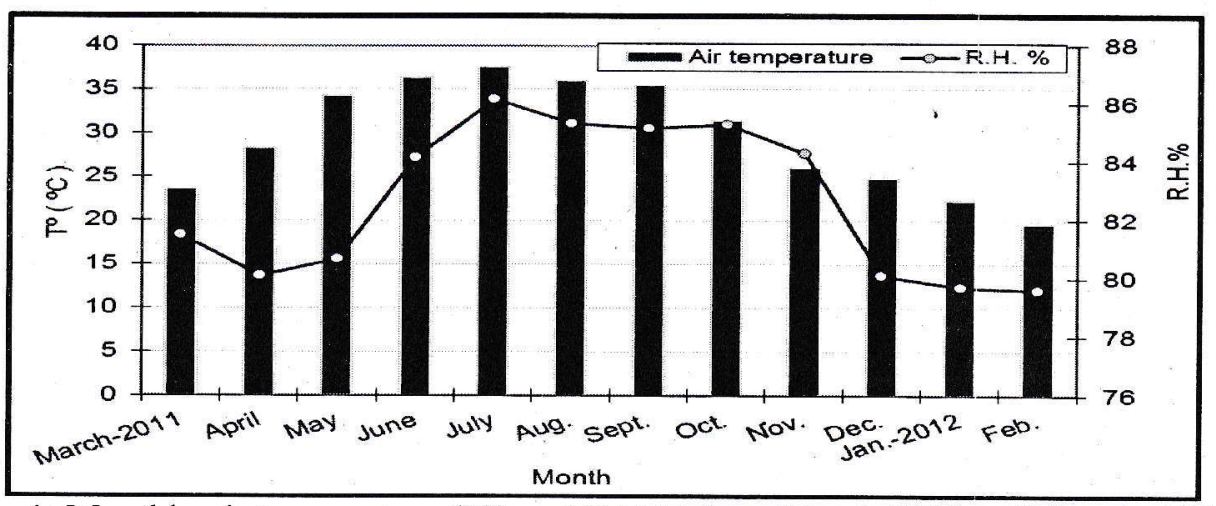

Fig. 1: Monthly air temperature $\left({ }^{\circ} \mathrm{C}\right)$ and R.H.\% from March 2011 to February 2012. 


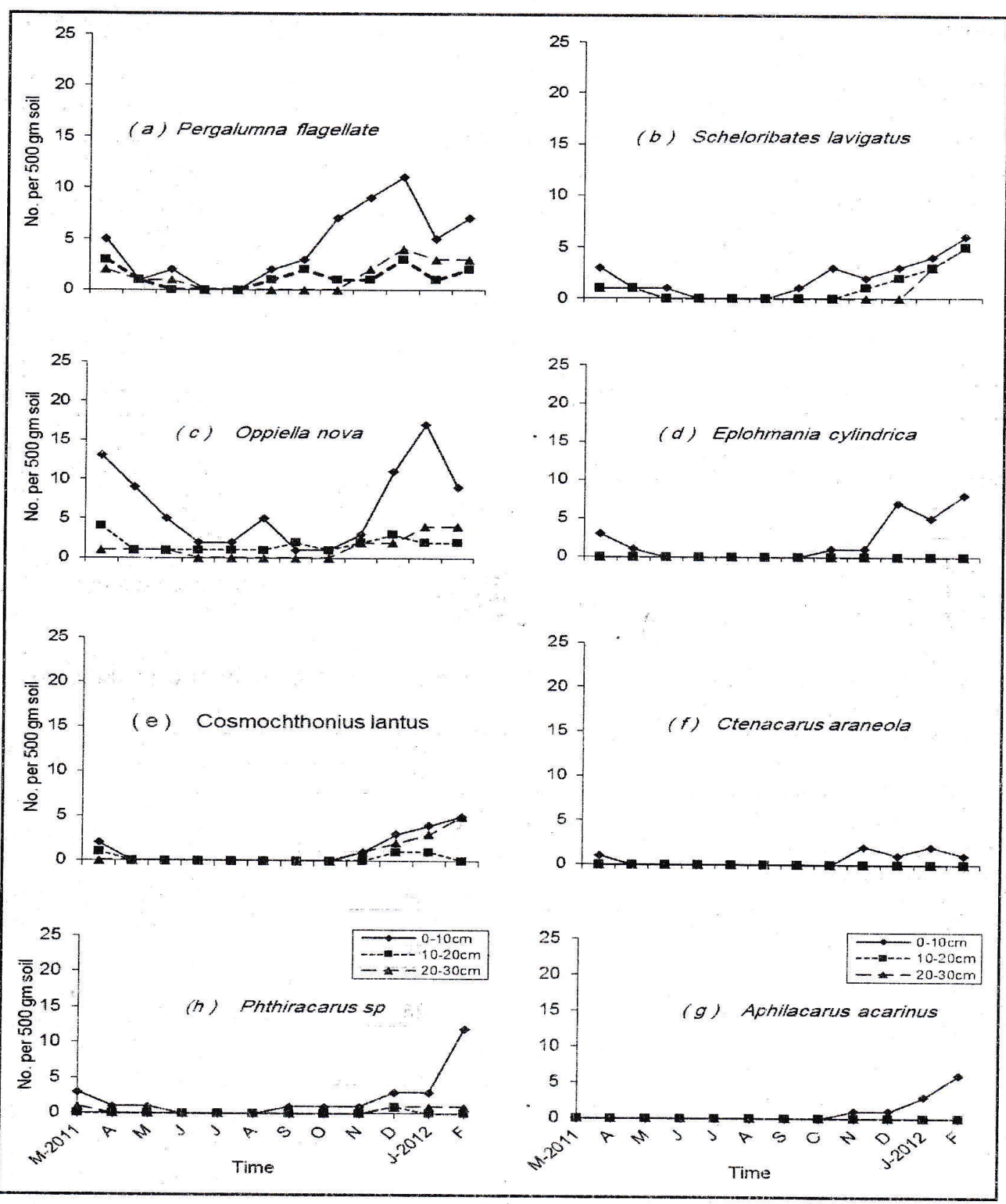

Fig. (2): Monthly fluctuations in numbers of the oribatid mite species at different soil depths during sapling time.

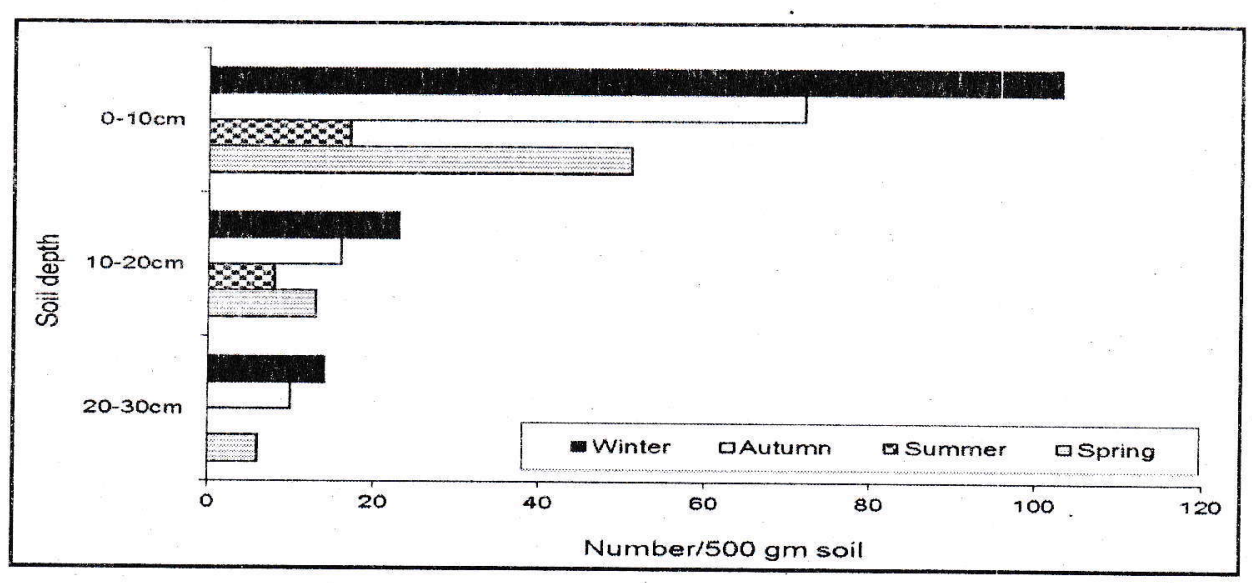

Fig. (3): The vertical distribution pattern of oribatid individuals according to sampling time. 
Scheloribates lavigatus (Koch) and Cosmochthonius lantus (Michael) were mainly concentrated in the upper two layers. Species density showed significant differences among soil layers $(P$ $<0.05, \mathrm{df}=5$ ), with a progressive decrease in the number of species from the first depth to the deepest level (Table 2). Diversity index $\left(\mathrm{H}^{\prime}\right)$ value of oribatid communities in the three depths were 2.41, 2.23, and 2.11, respectively. Evenness index $\left(\mathrm{J}^{\prime}\right)$ value of oribatid communities in the three depths were 0.63 , 0.67 , and 0.71 , respectively. There was significantly lower in abundance and species richness in oribatid mites in $10-20 \mathrm{~cm}$ and $20-30 \mathrm{~cm}$ depth than in 0 $10 \mathrm{~cm}$ depth. Aphilacarus acarinus (Berlese) were not collected in the depths $10-20 \mathrm{~cm}$ and $20-30 \mathrm{~cm}$, and it's composed the lowest fraction in the first depth.

Environmental factors throughout the year observed in the soil of the present study are suitable for oribatid community. The soil $\mathrm{pH}$ ranged from neutral to moderately alkaline ( $\mathrm{pH} 6.61-8.04$ ) on most sampling dates. This range appeared to be within tolerance of most species (Bedano et al., 2005), and due to plant cover that were favorable conditions for oribatid mites. The negative correlations of soil $\mathrm{pH}$ and mite numbers at different soil layers were $(r=-0.392,-0.439$ and -0.213 , respectively). On the other hand, EC showed positive correlation with mite numbers $(r=0.150$, 0.244 and 0.174 , respectively).

Organic matter content (OMC) ranged from $0.41 \pm 0.01$ to $0.59 \pm 0.06 \%$. Its percentage in the soil under investigation was low. OMC correlated positively with mite density at three soil depths ( $r=$ $0.638,0.750$ and 0.488 , respectively). It is well known that soil organic matter content is usually beneficial for most soil animal groups (Noti et al., 2003), and that biodiversity is relatively strongly linked to available energy resources and essential nutrients. This agreement with numerous studies found correlation however between the organic matter content and the structure of oribatid communities (Bedano et al., 2005; Salmon et al., 2006). All mite groups recorded in this study were positively correlated with organic matter content. This association pattern is consistent with the observation of Abo-Korah (1979).

Percentage moisture content was higher at the top layer than the others. Correlation analysis showed positive correlation between percentage moisture content and mite numbers at $0-10 \mathrm{~cm}(r=0.522)$, while negative correlation occurred at $10-20$ and 20 $30 \mathrm{~cm}$ ( $r=-0.439$ and -0.312 , respectively).
Peterson and Luxton (1982) observed that the presence of soil mites in a bimodal distribution was correlated with soil moisture and root biomass. Badejo (1990) found a significant positive correlation between percentage of moisture content and total mite numbers in the forest plot while in the cassava plot the positive correlation was not significant.

Low densities of oribatid mites during the summer in this study could be attributed to high soil temperature. This assessment agrees with observations that temperature was more important as a regulator of microarthropod abundance than soil moisture in some experimental studies (Abo-Korah, 1979; Whitford, 1989; Bardgett and Cook 1998). Soil temperature had negative correlations with mite numbers at the three soil depths, $(r=-0.440,-0.438$ and -0.269 , respectively). High soil temperatures have been reported to reduce or prevent egg-laying and cause mortality of the sperm of mites, thereby leading to a decrease in the size of mite populations (Badejo, 1990).

Winter was more suitable for some oribatid species such as $P$. flagellate and $O$. nova. Migration of such species up and down in the soil was more noticeable (fig. 2) than other species. Increase of population density in the top layer, may be due to the green cover of the tree that protect the fauna from unsuitable temperature and light and might improve the environmental conditions. Al- Assiuty et al., (1993), reported that soil mites reached maximum density in spring and winter and a minimum density in summer. Soil moisture lowers soil temperature during summer but raises it during winter; since rain is scarce in Egypt, soil moisture is mainly provided by irrigation. Soil moisture is one of the most decisive factors affecting the life of oribatid communities (Georges and Hufrage1, 2009).

Species density and abundance of oribatid mites decreased gradually with soil depth, as previously reported in other ecosystems. S. lavigatus, was found in the top layer $(0-10 \mathrm{~cm})$, during the time of sampling in search of fungal hyphae which formed a large part of the food (Gulvik, 2007).

This pattern of variability in the different soil layers, principally related to seasonal environmental variations, may be a common feature in soil communities as suggested by the occurrence of vertical migrations in diverse soil inhabiting taxa in different systems (Frouz et al., 2004). It is obvious that soil oribatids can avoid the effect of unsuitable conditions by the ability of vertical migration. This 
interpreted the presence of some oribatids during the hottest period.

The vertical arrangement of oribatid mites in the soil profile was not permanently fixed. These changes may have been affected not only by the emergence of new forms and death of old ones, but also by the movements from one layer to another. Reduction in the abundance and aggregation of individuals in deeper layers may be due to less available of food sources and corresponding unfavorable microclimate condition. In fact, there were differences in diversity between the top layer on the others, with the former maintaining a higher diversity from the other levels, as previously indicated for Wafa et al., (1965) and Abo-Korah, (1979).

In general, vertical distribution, the total number of species recorded and abundance noted in this study are difficult to compare with several other published studies because of different sampling sites. However, overall values of oribatid species abundance obtained in this study are comparable with those given for soil under different land changes (Wafa et al., 1965; Abo-Korah, 1979), whereas substantially higher densities of soil oribatids have been recorded in some areas. The basic information on the influence of edaphic factors on the vertical distribution of oribatid mites in mango plantation in Egypt, especially at Ismailia district is necessary. So, this study provides important information on the factors affecting the vertical distribution and seasonal changes of some oribatid mite species in Egypt for studies of bioindicators of soil quality.

\section{ACKNOWLEDGMENT}

The author would like to thank Dr Ahmed Ibrahim, Soil and Water Department (Suez Canal University), for soil analysis and his help during the field work.

\section{REFERENCES}

Abo-Korah, S. M. 1979. Distribution and seasonal abundance of the soil mites associated with citrus trees in Monoufeia governorate, Egypt. Bull. Soc. Ent. Egypt, 62: 263-267.

Al-Assiuty, A. I. M., Bayoumi, B. M.; Khalil, M. A. and Van Straalen, N. M. 1993. The influence of vegetation type on seasonal abundance and - species composition of soil fauna at different localities in Egypt. Pedobiologia, 37: 210-222.

Badejo, M.A. 1990. Seasonal abundance of soil mites (Acarina) in two contrasting environments. Biotropica, 22 (4): 382-390.

Balogh, J. 1972. The oribatid genera of the world. 330 pp. Akademicai Kiado, Hungari Budapest.

Banerjee, S.; Sanyal, A. K. and Moitra, M. N. 2009. Abundance and group diversity of soil mite population in relation to four edaphic factors at Chintamani Abhayaranya, Narendrapur, South 24-Parganas, West Bengal. Proc. Zool. Soc., 62 (1): 57-65.

Bardgett, R.D. and Cook, C.R. 1998. Functional aspects of soil animal diversity in agricultural grasslands. Appl. Soil Ecol., 10: 263-276.

Bedano, J.C., Cantu, M.P. and Doucet, M.E. 2005. Abundance of soil mites (Arachnida: Acari) in a natural soil of central Argentina. - Zoological Studies, 44(4): 505-512.

Behan-Pelletier, V.M. 1999. Oribatid mite biodiversity in agroecosystems: role for bioindication. Agriculture Ecosystems and Environment, 74: 411-423.

Edsberg, E. ; Hagvar, S. 1999. Vertical distribution abundance and biology of oribatid mites (Acari) developing inside decomposing spruce needles in a podsol soil profile. Pedobiologia, 43:413-421.

El-Sharabasy, H.M. and Ibrahim, A. 2010. Communities of oribatid mites and heavy metal accumulation in oribatid species in agricultural soils in Egypt impacted by waste water. Plant Protect. Sci., 46(4): 159-170.

Frouz, J., Ali, A., Frouzova, J. and Lobinske, R. 2004. Horizontal and vertical distribution of soil macro-arthropods along aspatio-temporal moisture gradient in subtropical central Florida. Environ. Entomol.,33 (5): 1282-1295.

Gregoes, V. and Hufnagel, L. 2009. Application of oribatid mites as indicators. (Review). Applied Ecology and Environmental Research, 7(1):7998.

Gulvik, M.E. 2007. Mites (Acari) as Indicators of soil biodiversity and land use monitoring: a Review. Pol. J. Ecol., 55(3): 415-440.

Jackson , M.L. 1967. Soil Chemical Analysis. Englewood Cliffs, Prentice Hall.

Magurran, A. E. 1988. Ecological diversity and its measurement. 179 pp. Cambridge University Press, London.

Noti, M. I.; Andre, H. M.; Ducarme, X. and Lebrun, P. 2003. Diversity of soil oribatid mites (Acari: Oribatida) from High Katanga (Democratic Republic of Congo): a multiscale and multifactor approach - Biodiversity and Conservation, 12(4): 767-785.

Perdue, J.C. and Crossley, D.A. 1990. Vertical distribution of soil mites (Acari) in conventional and no-tillage agricultural systems. Biology and 
fertility of soils, 9:135-138.

Petersen, H., Luxton, M. 1982. A comparative analysis of soil fauna populations and their role in decomposition processes. Oikos, 39: 288-388.

Pielou, E. C. 1984. The interpretation of ecological data. A primer on classification and ordination, 263 pp. John Wiley \& Sons, Singapore.

Salmon, S.; Mantel, J.; Frizzera, L. and Zanella, A. 2006. Changes in humus forms and soil animal communities in two developmental phases of Norway spruce on an acidic substrate. Forest Ecology and Management, 237(3): 47-56.

Siepel, H. 1996. Biodiversity of soil mcroarthropods the filtering of species. Biodiversity and conservation, 5: 251-260.

Soil Survey Staff, 1998. Keys to Soil Taxonomy, 8th ed. USDA, Natural Resources Conservation Service. U.S. Government Printing Office, Washington, DC, 326 p.

Wafa, A. K.; El-Kifl, A. H. and Tadros, M. S. 1965. Ecological studies on oribatids in Giza region. Bull.Soc.Ent.,49:281-317.

Wallwork, J. A. 1958. Notes on the feeding behavior of some forest soil mites. Oikos, 9: 260-271.

Whitford, W.G. 1989. Abiotic controls of the functional structure of soil food webs. Biol. Fert. Soils, 8: 1-6. 